\title{
Geohazard research, modeling, and assessment for disaster risk reduction
}

\author{
A. T. Ismail-Zadeh ${ }^{1,2}$ \\ Received 25 August 2016; accepted 27 August 2016; published 31 August 2016.
}

Scientific understanding of lithosphere dynamics, earthquake occurrence, volcanic eruption, lava flow and other geohazards events as well as geophysical hazard assessments are greatly advanced for the last several decades. Meanwhile despite these major advancements, yet we are not seeing significant disaster risk reduction and a concomitant decline in disaster impacts and losses. There are at least two major issues that should be improved before significant reduction in disaster losses: enhancing geohazards research and integrating it into disaster risk analysis and risk assessment, and convolving the research with policymaking. This paper, presented at the international conference "Data Intensive System Analysis for Geohazard Studies" (Sochi, Russia, 2016), highlights the importance of geohazards studies as a contribution to integrated research on disaster risk. To improve hazard assessments, I present here (i) an alternative approach to the seismic hazard analysis involving information on recorded, historic and simulated earthquakes as well as (ii) advanced quantitative modeling of lava flows due to effusive volcanic eruptions. Risk assessment efforts toward a reduction of disasters are then discussed in the framework of system analysis approach. KEYWORDS: geological hazards; geohazards; hazard assessment; risk; earthquake; lava flow; modeling; mathematical geophysics.

Citation: Ismail-Zadeh, A. T. (2016), Geohazard research, modeling, and assessment for disaster risk reduction, Russ. J. Earth. Sci., 16, ES3002, doi:10.2205/2016ES000572.

\section{Introduction}

Disasters triggered by geohazard events (earthquakes, volcanoes, landslides, and associated tsunamis) continue to grow in impact mainly due to vulnerability. In many regions, geohazards are becoming direct threats to national security because their impacts are amplified by rapid growth of population, and unsustainable development practices both of which increase exposure and vulnerabilities of communities, capital, and environmental assets. Reducing disaster risk using scientific knowledge is a foundation for sustainable development.

Geohazard research and hazard assessments are essential scientific inputs into understanding of disaster triggers. Meanwhile despite well-developed geohazards research, our knowledge on geohazards and their interaction with human systems is lacking in some important areas and is being chal-

\footnotetext{
${ }^{1}$ Institute of Earthquake Prediction Theory and Mathematical Geophysics, Russian Academy of Sciences, Moscow, Russia

${ }^{2}$ Institute of Applied Geosciences, Karlsruhe Institute of Technology, Karlsruhe, Germany

Copyright 2016 by the Geophysical Center RAS.

http://elpub.wdcb.ru/journals/rjes/doi/2016ES000572-res.html
}

lenged by a rapidly changing and increasingly interdependent world complicated by technological change, globalization of economic systems, and political and economic instability. In such a tightly coupled world a disaster not only affects the immediate area where it occurs, but also has cascading impacts that can affect other nations near and far. Integrated research on disaster risk and science-based disaster risk assessments coupled with political decisions could significantly reduce disasters [Cutter et al., 2015].

In this paper, advances in recent modeling of seismic and lava flow hazards are presented, and contributions of hazard analysis, modeling and assessments to disaster risk reduction are discussed. Section 2 discusses how lithosphere dynamics is associated with geophysical phenomena such as earthquakes or volcanoes. Section 3 describes principal seismic hazard assessment methods highlighting their advantages and challenges. Numerical modeling of extreme seismicity is then discussed in Section 4 with the aim to improve hazard analysis by involving recorded, historical and modeled seismic events. In Section 5, advanced modeling of lava flow is briefly presented with the aim to enhance lava hazard assessment. Section 6 discusses geohazards and risks in the framework of transdisciplinary, system-analysis approach to disaster reduction, and concluding remarks are presented in Section 7 


\section{Lithospheric Dynamics}

Observations of high seismic activities and large gravity anomalies, associated with oceanic trenches, resulted in the hypothesis that trenches are the sites of crustal convergence and consumption compared to surface augmentation at seafloor spreading zones [Hess, 1962]. As the lithosphere moves away from an oceanic ridge, it cools, densities, and thickens. Once the lithosphere becomes sufficiently dense compared to the underlying mantle rocks, it bends, founders, and begins sinking into the hot mantle due to gravitational instability. The downward buoyancy forces promote the sinking of the lithosphere, but elastic, viscous and frictional forces resist the descent. The combination of these forces produces tectonic stresses high enough to cause earthquakes. Other processes contributing to stress generation in the descending lithosphere and its release in earthquakes can be plastic instability at high temperature [Griggs and Baker, 1969, faulting due to metamorphic phase transitions [Green and Burnley, 1989], dehydration-induced embrittlement [Ismail-Zadeh et al., 2000], and some others. Earthquakes occur as a sudden release of stresses. When an earthquake occurs, part of the released energy generates elastic waves propagating through the Earth. These waves generate ground motions and shaking, which may result in building damage or collapse, landslides, tsunami wave generation, etc.

Oceanic trenches are the sites of the world largest earthquakes. The earthquakes at oceanic trench zones can occur along the descending lithosphere to the depths of about 700 $\mathrm{km}$ depending on the thermal state in the mantle. Meanwhile large earthquakes occur not only in subduction zones, but also inside of continents (so called 'intraplate earthquakes') especially in the regions of continental collisions, rifts, and grabens. For example, intermediate-depth earthquakes in the southeastern Carpathians (Vrancea) are associated with the relic collision zone [Ismail-Zadeh et al., $2012 \mathrm{~b}$.

Volcanoes are associated with lithospheric plates both converging (near subduction zones) or diverging (e.g. at the mid-Atlantic ridge). Meanwhile volcanoes can also form in the areas of crustal stretching (rifting), such as in the East African Rift, and are considered to be associated with mantle plumes or hot spots. Erupting volcanoes may pose hazards because of lava flow and volcanic ash, which can be a threat to people causing respiratory distress and to aircraft's jet engines. Large volcanic eruptions can influence Earth's temperature and climate [Oppenheimer, 2003.

Landslides are triggered by earthquakes, volcanic eruptions, rainfalls, and associated soil liquefaction; submarine landslides in the ocean floor can trigger tsunami waves. Landslides and concatenated events may impact vulnerable population and lead to disasters. Moreover, climate change may intensify the risk of landslides through an increase in the frequency and magnitude of rainfall.

\section{Seismic Hazard Analysis}

Seismic hazard can be defined as a potentially damaging earthquake, which may cause injury or the loss of life, property damage, social and economic disruption, or environmental degradation. Seismic hazard assessment (SHA) in terms of engineering parameters of strong ground motion (namely, peak ground acceleration and seismic intensity) is based on the information about the features of excitation of seismic waves at the source, seismic wave propagation (attenuation), and site effect in the region under consideration and combines the results of seismological, geomorphological, geological, and tectonic investigations and modeling [IsmailZadeh, 2014 .

Two principal methods are intensively used in seismic hazard assessment: probabilistic and deterministic SHA. The probabilistic SHA determines the probability rate of exceeding various levels of ground motion estimated over a specified period of time [Cornell, 1968]. The probabilistic assessment considers uncertainties in earthquake source, path, and site conditions. The uncertainties are classified as epistemic and aleatory. Epistemic uncertainties reflect the incomplete knowledge about input model parameters to the assessment and variability of interpretations of available data. Aleatory uncertainties consider the inevitable unpredictability of the parameters: the uncertainties are mainly quantified through the use of the standard deviation of the scatter around the mean values. Although the probabilistic SHA method is dominant in hazard assessment, there are several points of criticism related to this assessment: e.g., validity of a point source model; ground motion uncertainties in the mathematical formulation of the method; and challenges in modeling of the dependencies between large numbers of uncertain random parameters [Panza et al., 2010.

The deterministic SHA is an alternative method for hazard analysis and is based on a specified earthquake scenario. For a given earthquake, the deterministic assessment model analyzes the attenuation of seismic energy with distance to determine the level of ground motion at a particular site. Ground motion calculations capture the effects of local site conditions and use the available knowledge on earthquake sources and wave propagation processes. Namely, attenuation relationships are used for a given earthquake magnitude to calculate ground shaking demand for rock sites, which is then amplified by factors based on local soil conditions. Although the occurrence frequency of the ground motion is usually not addressed in the deterministic SHA, the method is robust for an assessment of seismic hazard due to specified events and remains a useful approach for a decision-making [Babayev et al., 2010].

The last decade's parade of extreme seismic events (2004 Sumatra-Andaman, 2005 Kashmir, 2008 Wenchuan, 2010 Chile, 2011 Tohoku, and 2015 Nepal earthquakes) demonstrated that big magnitude events come as a surprise, although a scientific knowledge about historical large earthquakes was available in the most of the regions where the great and large earthquakes occurred. However, many existing seismic hazard maps did not mark the regions as those of significant hazards, but instead the maps present a level of 


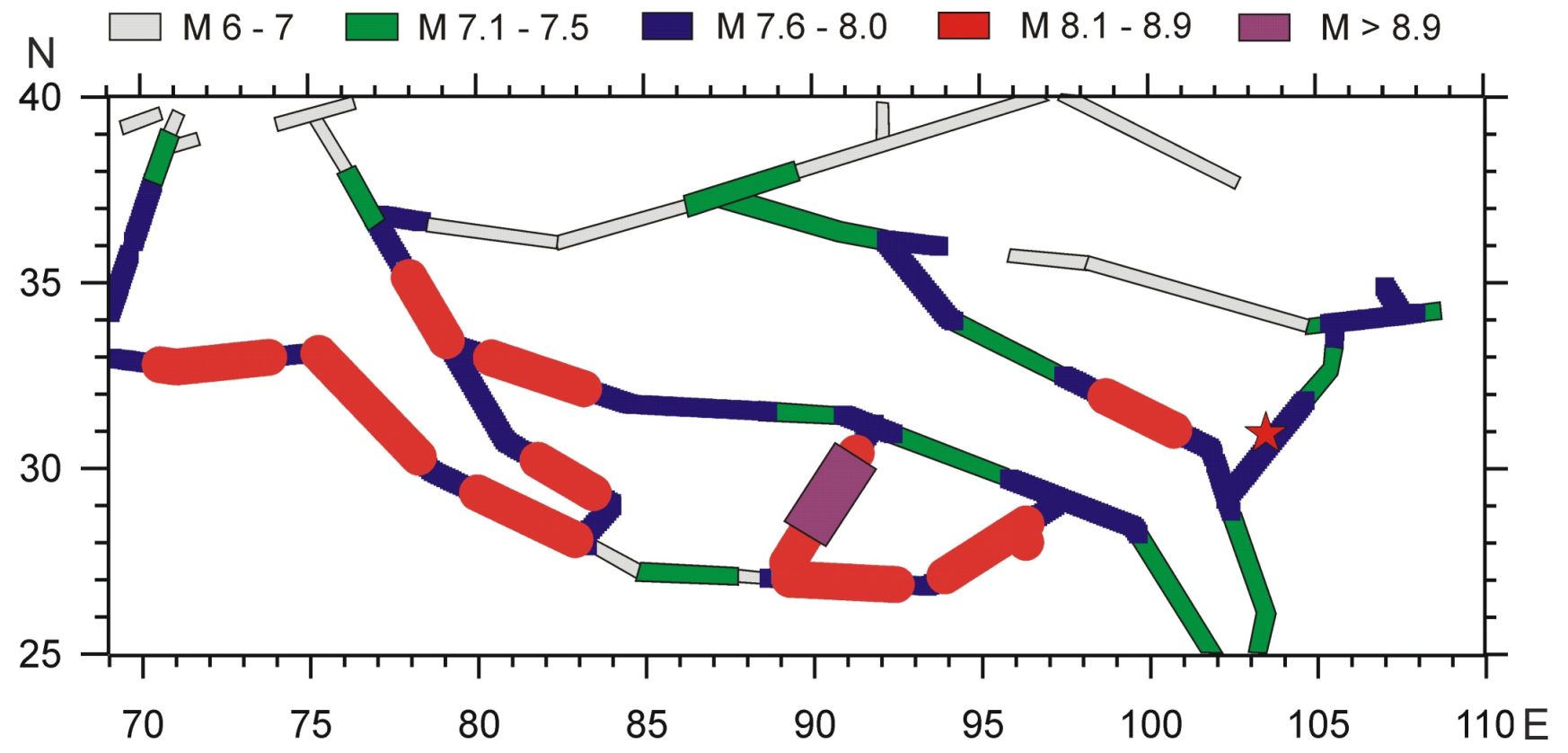

Figure 1. Distribution of maximum magnitudes of the earthquakes along major fault planes predicted by the BAFD model for the Tibet-Himalayan region [Ismail-Zadeh et al., 2007b]. Alter Sokolov and Ismail-Zadeh, 2015.

ground shaking, which can be exceeded with a certain probability within a certain time period. That is, the maps provide a low bound of seismic hazard useful for engineers but not much for people living in earthquake-prone regions. Ground shaking due to recent large earthquakes was much higher than expected [Stein et al., 2011], and hence, the numbers of fatalities in recent earthquake disasters were underestimated by approximately two to three orders of magnitude [Wyss et al., 2012]. This reveals a weakness in current seismic hazard assessment, which is mostly engineering-oriented and not human-oriented.

In many cases, large earthquakes are not accounted in the probabilistic SHA mainly due to the lack of information about them and unknown reoccurrence time of the extremes. Our present knowledge about characteristics of seismicity is based on observed (recorded) and sometimes on historical data (from paleoseismological and archaeological studies, written stories about intensities of large earthquakes and some others sources). The information about extreme events in a particular region is incomplete as the large events are rare. Modeling of extreme seismic events using earthquake simulators is a way to overcome the difficulties in seismic hazard assessment by combination of observations, historic data and modeled results.

\section{Earthquake Simulator and Hazard Assessment}

Studying seismicity using the statistical and phenomenological analysis of earthquake catalogs has the disadvantage that instrumental observations cover a short time interval compared to the duration of the tectonic processes responsi- ble for earthquakes. The patterns of earthquake occurrence identifiable in a catalog may be apparent and yet may not be repeated in the future. Moreover, the historical data on seismicity are usually incomplete. Numerical modeling of seismogenic processes allows generating synthetic earthquake catalogs covering very long time intervals and, therefore, providing a basis for reliable estimates of the parameters of the earthquake occurrences [Soloviev and IsmailZadeh, 2003 Ismail-Zadeh et al., 2012a. Tectonicallyrealistic earthquake simulators help to generate seismicity for a big interval of time and to study the synthetic seismic events so obtained.

Gabrielov et al. 1990 developed a lithospheric blockand-fault dynamics (BAFD) model, which was designed to answer the important questions: how upper crustal (or lithospheric) blocks react to the plate motions and to a flow of the lower ductile crust (or asthenosphere); how earthquakes cluster in the system of major regional faults; at which part of a fault system large (extreme) events can occur, and what is the occurrence time of the extreme events; how the properties of the frequency-magnitude relationship change prior extreme events; how fault zones properties influence the earthquake clustering, its magnitude and fault slip rates.

Using a BAFD model, Ismail-Zadeh et al. 2007b developed numerical experiments to analyze the earthquake clustering, frequency-to-magnitude relationships, earthquake focal mechanisms, fault slip rates, and frequency of large events in the Tibet-Himalayan region. Synthetic seismicity spanned over 4000 years, a considerably longer interval of time compared to the duration of the recorded regional seismicity (Figure 1). The biggest magnitude of the synthetic events was found to be $M=8.9$. These events occurred five times at the same fault. It was shown that the reoccurrence time of the largest events varied from about 1200 


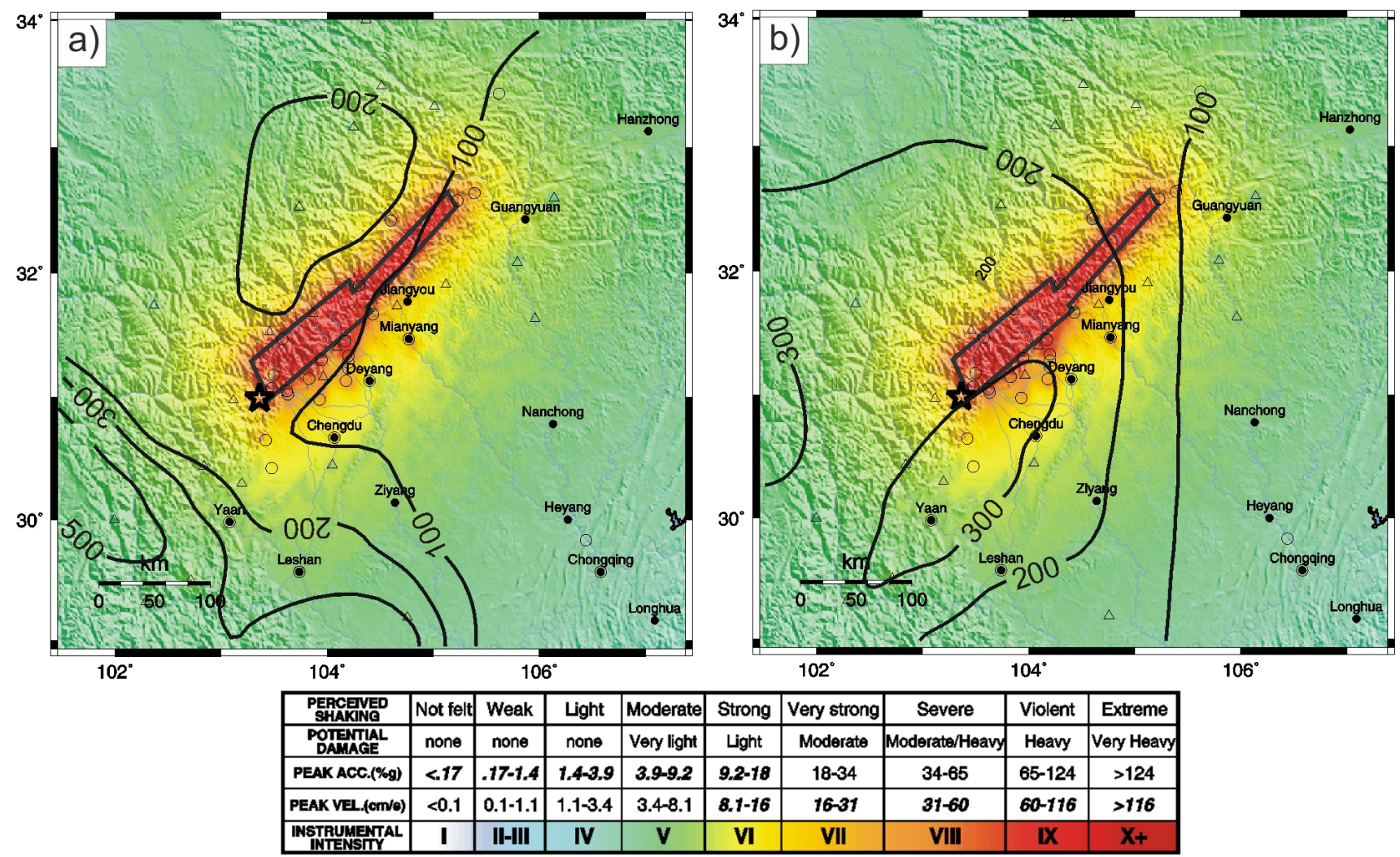

Figure 2. Comparison of instrumental intensity (USGS shake map for the 2008 Wenchuan earthquake shown in the background) with the peak ground accelerations (in $\mathrm{cm} \mathrm{s}-2$; for rock site conditions and the return period of 475 years) taken from (a) the Global SHA Program (GSHAP) data [Giardini et al., 1999 and (b) from the SHA results by Sokolov and Ismail-Zadeh, 2015.

to 50 years. It is remarkable to mention that the BAFD model identified a cluster of large synthetic events (magnitude about 8 , see Figure 1) along the Longmen Shan fault before the 2008 Wenchuan $M=7.9$ earthquake occurred at this fault [Ismail-Zadeh et al., 2007b].

Earthquake simulators are not only tools for studying seismic preparation processes, but also can be useful in hazard assessment. Using the Monte-Carlo probabilistic SHA, Sokolov and Ismail-Zadeh 2015 developed a new approach to hazard assessment incorporating large magnitude synthetic events obtained by BAFD simulations consistent with the geophysical and geodetic data as well as the observed earthquakes into the ground motion estimation. Earthquake scenarios for hazard assessment are generated stochastically to sample the magnitude and spatial distribution of seismicity, as well as the distribution of ground motion for each seismic event. They applied this approach to hazards analysis in the Tibet-Himalayan region. Figure 2 compares the results of the hazard assessment for the Eastern Sichuan (China) obtained by two methods: the standard probabilistic SHA [Giardini et al., 1999 and the assessment method proposed by Sokolov and Ismail-Zadeh 2015. The peak ground acceleration in the new hazard model is by a factor of 2 to 3 greater than that in the standard hazard model, and hence better explains observed shaking due to the 2008 Wenchuan
$M_{W} 7.9$ earthquake. The data-enhanced seismic hazard assessment by Sokolov and Ismail-Zadeh 2015 may provide a better understanding of ground shaking and could be useful for earthquake risk assessment, engineering purposes, and emergency planning.

Seismic hazard assessment is usually performed at individual sites and not within a region of specific interest. Sokolov and Ismail-Zadeh 2016] analyzed features of multiple-site SHA, i.e. the annual rate of ground-motion level exceedance in at least one site of several sites of interest located within in an area or along a linear extended object. The authors showed that the multiple-site probabilistic SHA, when being performed for the standard return period 475 years, provides reasonable estimations of the intensity level that may occur during the earthquakes, parameters of which are close to the parameters of events with maximum possible magnitude accepted in probabilistic SHA for studied regions. Sokolov and Ismail-Zadeh 2016 proposed a multilevel approach to probabilistic SHA considering fixed reference probability of exceedance (e.g. $10 \%$ in 50 years): (i) a standard point-wise hazard assessment to be performed in a seismic-prone region, and (ii) this analysis should be supplemented by a multiple-site hazard assessment for urban and industrial areas, or zones of a particular economic and social importance. 
a)

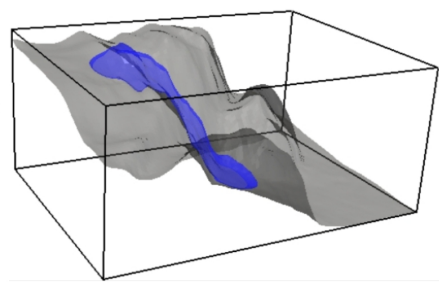

b)

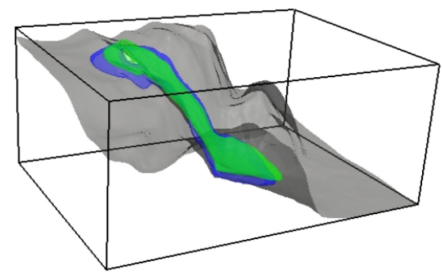

c)

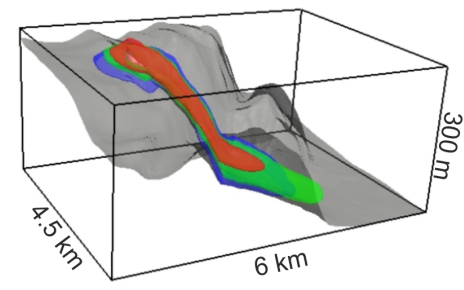

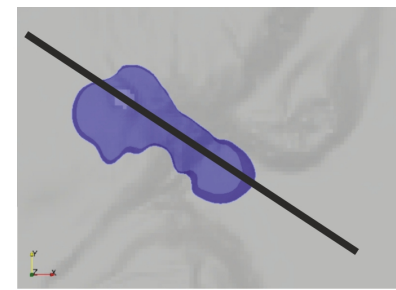
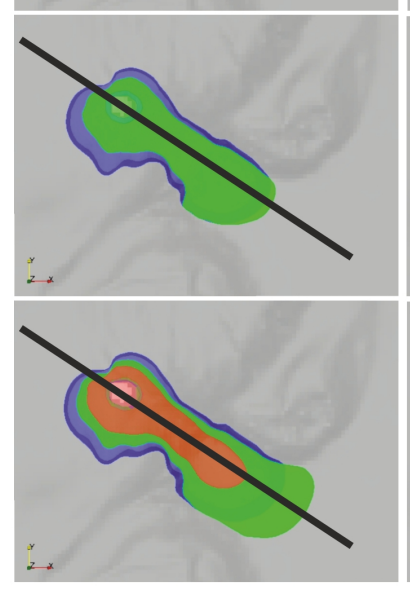

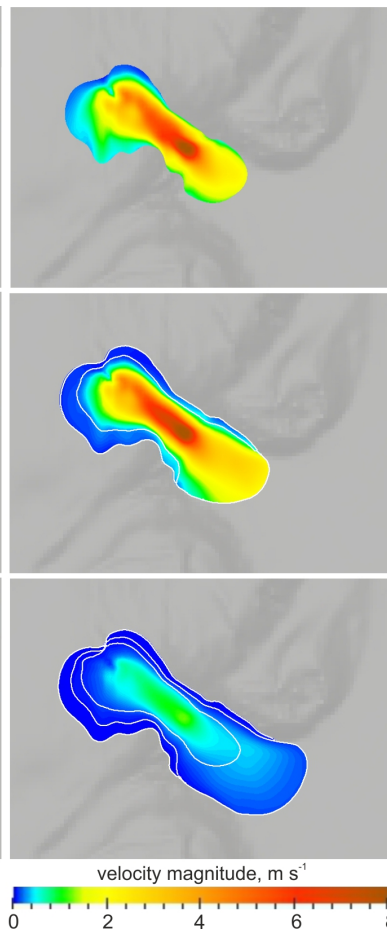

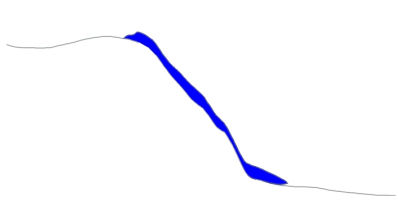

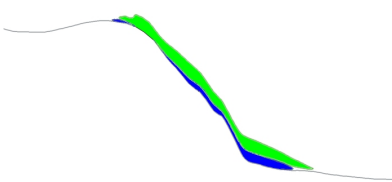

Figure 3. Lava flow snapshots at times $9000 \mathrm{~s}$ (a), $33000 \mathrm{~s}$ (b), and $63000 \mathrm{~s}$ (c). Blue-, green-, and red-colored lavas are modeled fluids 1, 2, and 3, respectively (see Table 1 for their physical properties). Each time snapshot presents three views: a 3-D view (left panels), a view from the top (middle-left panels), and a cross-section view (right panels) as well as the velocity magnitude (middle-right panels). The black solid lines (in the middle-left panels) present the position of the cross section. The white curves (in the middle-right panels) show the extend of lava flow at the end of the second and third episodes of lava effusion. After Tsepelev et al. 2016.

\section{Lava Flow Modeling}

During volcanic non-explosive (effusive) eruptions, partially molten rocks are erupted onto the Earth's surface, spread slowly on the surface from the volcanic edifice, and generate lava flows. The eruptions produce a variety of currents depending on the chemical composition and temperature of the magmatic rocks, and the topography of the surface over which the lava flows [Griffiths, 2000]. Under relatively steady eruption conditions, lava flow rapidly forms a solid crust. Cooling and crystallization of the uppermost layer of the moving melt lead to a gravity current of lava under a solid crust, which insulates the lava flow interior. The crust preserves the lava against rapid cooling and permits the lava flow extending to substantial distances. Eventual ruptures of the crust and a generation of the crustal pieces results in lava/debris flow, which enhances hazard.

Computer simulations play an important role in understanding the dynamics and thermal structures of lava flows and in hazard assessment [Costa and Macedonio, 2005, and references herein]. Tsepelev et al. 2016 developed threedimensional numerical models of a lava flow with rigid crustal fragments and performed a series of deterministic numerical simulations to analyze the spatial-temporal distribution of the rafts depending on their size, a topographic slope, multiple sources of effusion, the variation of physical properties of a fluid, and boundary conditions. Particularly, they considered a model describing lava flow, when an eruption gives lava with changing composition with time. A solution to the model can provide a useful insight into the evolution of the eruption and improve lava flow hazard assessment.

The evolution of lava flows during three episodes of the modeled eruption is presented in Figure 3 the physical properties of the modeled lavas are presented in Table 1. Initially, lava (blue) flows down the slope for 2.5 hours. During the next episode of the eruption, a new portion of lava (green) with other physical properties starts to flow on the top of the blue lava for about 6.7 hours. As the viscosity of earlier lava becomes higher, it slowly moves down the slope together with new portion of lava as a results of gravity and isostatic squeezing of older lava by hotter younger lava. The maximum rate of lava flow is estimated to be about $8 \mathrm{~m} \mathrm{~s}^{-1}$, which is attained in the area of the model steepest topography (the middle-right panel in Figure 3 illustrates the distribution of velocity magnitudes). The third episode of the eruption starts from the same vent, but with the effusion rate, which is lower than the initial rate by a factor of 5 . Therefore, the maximum fluid velocity drops to about $1.2 \mathrm{~m} \mathrm{~s}^{-1}$. The newly injected lava flows on the top of two older and colder lavas pushing them down and further squeezing the underlying fluids. Finally, the computations are terminated after about 8.3 hours of the lava flow. The scenario of lava flows described above generates composi- 
Table 1. Physical parameters of modeled lavas

\begin{tabular}{|c|c|c|c|}
\hline Fluid & Density, $\mathrm{kg} \mathrm{m}^{-3}$ ) & Viscosity, $\mathrm{Pa} \mathrm{s}$ & Rate, $\mathrm{m} \mathrm{s}^{-1}$ \\
\hline \multicolumn{4}{|c|}{ Episode 1 (9000-s flow) } \\
\hline 1 & 2500 & $10^{7}$ & 0.5 \\
\hline \multicolumn{4}{|c|}{ Episode $2(24,000$-s flow $)$} \\
\hline 1 & 2500 & $10^{8}$ & 0 \\
\hline 2 & 2300 & $10^{7}$ & 0.5 \\
\hline \multicolumn{4}{|c|}{ Episode 3 (30,000-s flow) } \\
\hline 1 & 2500 & $10^{9}$ & 0 \\
\hline 2 & 2300 & $10^{8}$ & 0 \\
\hline 2 & 2300 & $10^{8}$ & 0.1 \\
\hline
\end{tabular}

tionally stratified lava flow containing several units. Due to lower viscosity green lava propagates faster and overcomes the initial blue lava. At any particular location the stratigraphy of the lava flow can depend on the eruption history in a complicated manner. For example, the front of the lava flow contains only the lava that was effused during the intermediate stage of eruption. Colling of the flow can preserve such stratigraphy, if the upper unit has sufficient time for solidification due to low effusion rate [Tsepelev et al., 2016].

An absolute temperature of the lava surface can be measured from the space (using satellites, airplanes or drones). Meanwhile the temperature and flow rate inside the lava flow are unknown, and very difficult to determine after a solidification of its uppermost part and development of a crust. Ismail-Zadeh et al. 2016 and Korotkii et al. 2016 proposed a new quantitative approach to determine thermal and dynamic characteristics of a lava flow from thermal measurements at its surface. This approach is based on a determination of the optimal temperature at the lower boundary of lava flow from the known heat flow at the lava's upper surface, and on a subsequent determination of the temperature and flow rates inside the lava. Mathematically this approach leads to solving an inverse boundary problem using a variational (adjoint) method. Korotkii et al. 2016] showed that in the case of smoothed measured data the lava temperature and its flow velocity can be reconstructed with a high accuracy, but noisy data degrade the accuracy of the solution.

Although lava flows slowly in many cases allowing for an evacuation of people from the areas of lava spreading, lava hazard is not negligible as hot lava kills vegetation, destroys houses, bridges, roads and other objects, and may melt snow/ice resulting in occasional flooding. The lava hazard can be mitigated if the flow patterns are known, and the complexity of the flow is investigated to assist in diverting the flow (e.g. by placing barriers which cut channels for the lava to follow) or in 'freezing' the lava flow with water [Fujita et al., 2009. Dietterich et al., 2015. Knowledge of lava flow paths and comprehensive lava hazard assessments can assist in disaster risk reduction efforts [Cutter et al., 2015].

\section{Risk Assessment}

Risk, in the context of geohazards, can be determined as the probability of harmful consequences or expected losses (of lives and property) and damages (e.g., people injured, economic activity disrupted, environment damaged) due to geophysical event(s) resulting from interactions between hazards $(\mathrm{H})$, vulnerability (V), and exposure (E). Conventionally, risk $(\mathrm{R})$ is expressed quantitatively by the convolution of these three parameters: (e.g. Kantorovich et al., 1973, for a methodology of seismic risk assessment). A physical vulnerability to earthquakes depends on several factors including the quality of building structures, ground conditions, and the distribution of population. An exposure accounts normally for infrastructure at risk.

A rapid growth of population, intensive civil and industrial building, land and water instabilities, and the lack of public awareness regarding hazards and risks contribute to the increase of vulnerability of big cities. For example, Babayev et al. 2010 assessed an earthquake risk in Baku (Azerbaijan) based on the convolution of scenariobased seismic hazards, vulnerability (due to building construction fragility, population features, the gross domestic product per capita, and landslide's occurrence), and exposure of infrastructure and critical facilities. One of the remarkable results of this assessment was the fact that the western-central part of the city is exposed to the highest risk independent on the magnitude and epicentral distance of modeled earthquakes. This is because of the physical vulnerability characterized by low quality of building constructions, high density of population, and significant exposed values in this part of the city.

With economic and technological development more and more structural elements (and sometimes the entire infrastructure) become exposed to risks due to geohazards. Risk assessment allows elaborating strategic countermeasure plans for disaster risk mitigation. An estimation of risks may facilitate a proper choice in a wide variety of safety measures, ranging, in the case of earthquakes, from building codes and insurance to establishment of rescue-and-relief resources. Most of the practical problems require estimating risk for a territory as a whole, and within this territory separately for the objects of each type: areas, lifelines, sites of vulnerable constructions, etc. The choice of the territory and the objects is determined by the jurisdiction and responsibility of a decision-maker. Each specific representation of risk is derived from the models of geohazards, the territorial distribution of population, property, vulnerable objects, and potential damage. Difficulties in decision making in the field of risk assessment are related to uncertainties in data (especially those related to social and physical vulnerabilities and exposure), imperfect methods for hazard assessment, and limitations in using mathematical tools for carrying out the historical analysis and forecasting.

One of the ways to understand why, where, when and how geohazards turn to become disasters is an integrated research on disaster risk, which combines knowledge from natural and social sciences with engineering and law, and convolves the knowledge with policymaking and disaster risk management. 
Such integrated research would be truly transdisciplinary (Stokols, 2006) aiming at in-depth investigations of a disaster problem using a system analysis approach and with recommendations for actions to reduce risks and to improve resilience of society. In the geoscience community, communication between, for example, seismologists, volcanologists, geodesists, and engineers exists but is still weak. When it concerns communication between geosciences and social sciences, scientists and policy makers, scientists and insurance representatives, the situation becomes even worse. All stakeholders dealing with disaster risk research should be properly bridged and strongly linked to each other by means of co-designed and co-productive research and actions.

Risk assessment efforts assist in optimizing preventive mitigation measures to reduce losses from catastrophic disasters. "If about 5 to $10 \%$ of the funds, necessary for recovery and rehabilitation after a disaster, would be spent to mitigate an anticipated earthquake, it could in effect save lives, constructions, and other resources - The tendency to reduce the funding for preventive disaster management of natural catastrophes rarely follows the rules of responsible stewardship for future generations neither in developing countries nor in highly developed economies" Ismail-Zadeh and Takeuchi, 2007a.

\section{Conclusion}

Geohazards were recognized as a grant challenge long time ago, and scientific community concentrated its efforts on solving the challenging problem with a significant progress achieved. A progress in geohazard (earthquakes, volcanoes, landslides, tsunami) assessments is based on in-depth analysis of individual hazards. In seismic hazard analysis, recent advances are associated with neo-deterministic approach to hazard assessment [Panza et al., 2010 and data-enhanced probabilistic SHA [Sokolov and Ismail-Zadeh, 2015]. Particularly, tectonically-realistic earthquake simulators help to generate seismicity for a big interval of time and to employ large synthetic seismic events for hazard assessment. Combined with pattern recognition techniques developed for identification of zones prone to earthquakes [Gvishiani et al., 2013 Soloviev et al., 2014, earthquake simulators may forecast the place of large events with higher accuracy. Similarly, advanced modeling of lava flows [Tsepelev et al., 2016. Korotkii et al., 2016 allows to trace different ways of lava extent enhancing hazard assessment. Meanwhile with time it was recognized that there are much more challenging problems including concatenated hazards and risk analysis including many components leading to a disaster. The problems affect society directly and require truly co-productive transdisciplinary studies and a system analysis approach.

In conclusion, I draw the attention of readers to several important scientific issues yet to be resolved in geohazard research and risk analysis: (i) Integrating research on geohazards through observations, monitoring, analysis, modeling, and interpretations; (ii) developing/enhancing comprehensive geohazard and risk assessment tools; (iii) reducing epistemic uncertainties in geohazard forecasting to improve the link between disaster mitigation community and the public; (iv) dealing with multiple and concatenated extreme events; (v) contributing to reduction of vulnerability by monitoring human systems at local, regional and global scales; and (vi) enhancing science education and improving awareness on extreme geohazards and disaster risks. Unless these challenging scientific issues are resolved and implemented in social and political actions, disaster losses due to geophysical hazard events impose a great challenge to sustainability [Ismail-Zadeh, 2014].

Acknowledgments. The work was supported in parts by the Russian Science Foundation (RSF project 14-17-00520) and the German Science Foundation (DFG project IS 203/4-1).

\section{References}

Babayev, G., A. Ismail-Zadeh, J.-L. Le Mouël (2010), Scenariobased earthquake hazard and risk assessment for Baku (Azerbaijan), Natural Hazard and Earth System Sciences, 10, 26972712, doi:10.5194/nhess-10-2697-2010

Cornell, C. A. (1968), Engineering seismic risk analysis, Bulletin of the Seismological Society of America, 58, 1583-1606.

Costa, A., G. Macedonio (2005), Numerical simulation of lava flows based on depth-averaged equations, Geophysical Research Letters, 32, L05304, doi:10.1029/2004GL021817

Cutter, S., A. Ismail-Zadeh, I. Alcántara-Ayala, et al. (2015), Pool knowledge to stem losses from disasters, Nature, 522, 277-279, doi:10.1038/522277a

Dietterich, H. R., K. V. Cashman, A. C. Rust, E. Lev (2015), Diverting lava flows in the lab, Nature Geoscience, 8, 494496, doi:10.1038/ngeo2470

Fujita, E., M. Hidaka, A. Goto, S. Umino (2009), Simulations of measures to control lava flows, Bulletin of Volcanology, 71 , 401-408, doi:10.1007/s00445-008-0229-7

Gabrielov, A. M., T. A. Levshina, I. M. Rotwain (1990), Block model of earthquake sequence, Physics of the Earth and Planetary Interiors, 61, 18-28, doi:10.1016/0031-9201(90)90091-B

Giardini, D., G. Grünthal, K. M. Shedlock, P. Zhang (1999), The GSHAP Global Seismic Hazard Map, Annali di Geofisica, 42, 1225-1228.

Green, H. W., II, P. C. Burnley (1989), A new self-organizing mechanism for deep-focus earthquakes, Nature, 341, 733-737, doi: $10.1038 / 341733 \mathrm{a} 0$

Griffiths, R. W. (2000), The dynamics of lava flows, Annual Review of Fluid Mechanics, 32, 477-518, doi:10.1146/annurev. fluid.32.1.477

Griggs, D. T., D. W. Baker (1969), The origin of deep-focus earthquakes, Properties of Matter Under Unusual Conditions (eds. H. Mark and S. Fernbach) p. 23-42, Wiley, New York.

Gvishiani, A. D., S. M. Agayan, M. N. Dobrovolsky, B. A. Dzeboev (2013), Objective classification of the epicenters and recognition of the earthquake-prone areas in California, Geoinformatika, 2, 44-57.

Hess, H. (1962), History of ocean basins, Petrologic Studies (eds. A. Engeln, H. L. James, and B. F. Leonard) p. 599-620, Geological Society of America, New York. doi:10.1130/petrolo gic.1962.599

Ismail-Zadeh, A., G. F. Panza, B. M. Naimark (2000), Stress in the descending relic slab beneath Vrancea, Romania, Pure and Applied Geophysics, 157, 111-130, doi:10.1007/PL0000 1090

Ismail-Zadeh, A., K. Takeuchi (2007a), Preventive disaster management of extreme natural events, Natural Hazards, 42, 459-467, doi:10.1007/s11069-006-9075-0

Ismail-Zadeh, A. T., J. L. Le Mouél, A. Soloviev, P.Tapponnier, I. Vorobieva (2007b), Numerical modeling of crustal block- 
and-fault dynamics, earthquakes and slip rates in the TibetHimalayan region, Earth and Planetary Science Letters, 258, 465-485, doi:10.1016/j.epsl.2007.04.006

Ismail-Zadeh, A., J.-L. Le Mouél, A. Soloviev (2012a), Modeling of extreme seismic events, Extreme Events and Natural Hazards: The Complexity Perspective (eds. S. A. Sharma, A. Bunde, V. P. Dimri, and D. N. Baker), Geophysical Monograph 196 p. 75-97, American Geophysical Union, Washington, D. C.. doi:10.1029/2011GM001080

Ismail-Zadeh, A., L. Matenco, M. Radulian, S. Cloetingh, G. Panza (2012b), Geodynamic and intermediatedepth seismicity in Vrancea (the south-eastern Carpathians): Current state-of-the-art, Tectonophysics, 530-531, 50-79, doi:10.1016/j.tecto.2012.01.016

Ismail-Zadeh, A. (2014), Extreme seismic events: from basic science to disaster risk mitigation, Extreme Natural Events, Disaster Risks and Societal Implications (eds. A. Ismail-Zadeh, J. Fucugauchi, A. Kijko, K. Takeuchi, and I. Zaliapin) p. 4760, Cambridge University Press, Cambridge. doi:10.1017/CBO 9781139523905.007

Ismail-Zadeh, A., D. Kovtunov, A. Korotkii, O. Melnik, I. Tsepelev (2016), Physical characteristics of a lava flow determined from thermal measurements at the lava's surface, Doklady Earth Sciences, 467, 367-370, doi:10.1134/S1028334X160 40036

Kantorovich, L., V. I. Keilis-Borok, G. Molchan (1973), Seismic risk and principles of seismic zoning, Computational and Statistical Methods for Interpretation of Seismic Data (ed. V. I. Keilis-Borok) p. 3-20, Nauka, Moscow. (in Russian)

Korotkii, A., D. Kovtunov, A. Ismail-Zadeh, I. Tsepelev, O. Melnik (2016), Quantitative reconstruction of thermal and dynamic characteristics of lava from surface thermal measurements, Geophysical Journal International, 205, 17671779, doi:10.1093/gji/ggw117

Oppenheimer, C. (2003), Climatic, environmental and human consequences of the largest known historic eruption: Tambora volcano (Indonesia) 1815, Progress in Physical Geography, 27, 230-259, doi:10.1191/0309133303pp379ra

Panza, G. F., K. Irikura, M. Kouteva, A. Peresan, Z. Wang, R. Saragoni (2010), Advanced seismic hazard assessment,
Pure and Applied Geophysics, 168, 1-9, doi:10.1007/s00024010-0179-9

Sokolov, V., A. Ismail-Zadeh (2015), Seismic hazard from instrumentally recorded, historical and simulated earthquakes: Application to the Tibet-Himalayan region, Tectonophysics, 657, 187-204, doi:10.1016/j.tecto.2015.07.004

Sokolov, V., A. Ismail-Zadeh (2016), On the use of multiple-site estimations in probabilistic seismic hazard assessment, Bulletin of the Seismological Society of America, 106(5), BSSA Early Edition/1-BSSA Early Edition/11, doi:10.1785/ 0120150306

Soloviev, A. A., A. T. Ismail-Zadeh (2003), Models of dynamics of block-and-fault systems, Nonlinear Dynamics of the Lithosphere and Earthquake Prediction (eds. V. I. KeilisBorok and A. A. Soloviev) p. 69-138, Springer, Heidelberg. doi:10.1007/978-3-662-05298-3_3

Soloviev, A. A., A.D. Gvishiani, A. I. Gorshkov, M. N.Dobrovolsky, O. V. Novikova (2014), Recognition of earthquake-prone areas: Methodology and analysis of the results, Izv., Phys. Solid Earth, 50, 151, doi:10.1134/S1069351314020116

Stein, S., R. Geller, M. Liu (2011), Bad assumptions or bad luck: why earthquake hazard maps need objective testing, Seismological Research Letters, 82, 623-626, doi:10.1785/gssrl.82.5.623

Stokols, D. (2006), Toward a science of transdisciplinary action research, American Journal of Community Psychology, 38, 63-77, doi:10.1007/s10464-006-9060-5

Tsepelev, I., A. Ismail-Zadeh, O. Melnik, Korotkii (2016), Numerical modelling of fluid flow with rafts: An application to lava flows, Journal of Geodynamics, 97, 31-41, doi:10.1016/j. jog.2016.02.010

Wyss, M., A. Nekraskova, V. Kossobokov (2012), Errors in expected human losses due to incorrect seismic hazard estimates, Natural Hazards, 62, 927-935, doi:10.1007/s11069012-0125-5

A. T. Ismail-Zadeh, Institute of Applied Geosciences, Karlsruhe Institute of Technology, Adenauerring 20b, 76131 Karlsruhe, Germany (alik.ismail-zadeh@kit.edu) 